\title{
História oral: consequências do ensino remoto na atuação de professores
}

\author{
Oral history: consequences of remote teaching on teachers performance
}

\author{
Historia oral: consecuencias de la enseñanza a distancia en el desempeño docente
}

\author{
Gleyton de Moura Ferreira Silva ${ }^{1}$ \\ Jocyleia Santana Dos Santos ${ }^{2}$ \\ Damião Rocha ${ }^{3}$
}

\begin{abstract}
Resumo
O objetivo deste trabalho é compreender, a partir do método da História Oral, como o ensino remoto emergencial impactou a vida docente nos anos de 2020 e 2021 no município Guaraí - TO. A pesquisa está estruturada em duas etapas: a primeira, de revisão bibliográfica e a segunda, na qual foram conduzidas as entrevistas temáticas com quatro entrevistados a partir de questões semiestruturadas que foram elaboradas pensando em incentivar a fala e a subjetividade, bem como servindo como um guia para o desenvolvimento e condução das entrevistas. Na seção de revisão bibliográfica pesquisamos sobre os conceitos de Ensino Remoto, Ensino Remoto Emergencial, além dos obstáculos e a formação de professores em relação ao uso de tecnologias. Ao todo foram conduzidas quatro entrevistas realizadas com profissionais da educação em atividade. Por último realizamos reflexões a cerda das entrevistas.
\end{abstract}

Palavras chave: História Oral; Ensino Remoto; Ensino Remoto Emergencial; Formação de Professores.

\begin{abstract}
The objective of this work is to understand, from the method of Oral History, how emergency remote teaching impacted the teaching life in 2020 and 2021 in city of Guaraí - TO. The research is structured in two stages: the first, a bibliographic review and the second, in which thematic interviews were conducted with four interviewees from semi-structured questions that were prepared thinking about

\footnotetext{
${ }^{1}$ Mestrando em Educação PPGE / UFT. Graduado em Ciências Biológicas pela FABEJA. Especialista em Saúde Pública pela FACETEG. Pesquisador do grupo de pesquisa CNPq/UFT Gepce/UFT. Bolsista CAPES demandas sociais. Lattes: http://lattes.cnpq.br/4259591257208988 e-mail:gleyton.ferreira@uft.edu.br Orcid: https://orcid.org/0000-0002-5621-5137

${ }^{2}$ Pós-doutora em Educação. Doutora em História. Coordenadora do Programa de Pós-graduação em Educação PPGE/UFT. Coordenadora do Polo Tocantins do Doutorado em Educação na Amazônia (PGEDA). Link Lattes:http://lattes.cnpq.br/8198025782417839.E-mail:jocyleiasantana@gmail.com. Orcid: http://orcid.org/00000003-2335-121X

${ }^{3}$ Pós-Doc. pela UEPA. Doutor em educação pela UFBA. Mestre em educação pela UFG. Docente do PGEDA/UFPA/UFT e PPGE/UFT. Vice-Presidente Norte da rede de Pesquisa Rides. Vice coordenador do Polo Palmas PGEDA/UFT. Coordenador do PPPGE/UFT. Líder do grupo de pesquisa Gepce/UFT email:damiao@uft.edu.br Lattes: http://lattes.cnpq.br/9799856875780031 Orcid: https://orcid.org/0000-0002$5788-7517$
}

Revista Devir Educação, Lavras, vol.5, n2., p.249-266 jul./dez., 2021. 


\section{OD DEVIR EDUCAÇÃO \\ ISSN: 2526-849X}

encouraging speech and subjectivity, as well as serving as a guide for developing and conducting the interviews. In the literature review section, we researched the concepts of Remote Teaching, Remote Emergency Teaching, in addition to obstacles and teacher training in relation to the use of technologies. In all, four interviews were conducted with active education professionals. Finally, we carry out reflections around the interviews.

Keywords: Oral History; Remote Teaching; Emergency Remote Learning; Teacher training.

\section{Resumen}

El objetivo de este trabajo es comprender, desde el método de Historia Oral, cómo la enseñanza remota de emergencia impactó la vida docente en 2020 y 2021 en la ciudad de Guaraí - TO. La investigación se estructura en dos etapas: la primera, una revisión bibliográfica y la segunda, en la que se realizaron entrevistas temáticas a cuatro entrevistados a partir de preguntas semiestructuradas que fueron elaboradas pensando en fomentar el habla y la subjetividad, además de servir como guía para desarrollo y realización de las entrevistas. En el apartado de revisión de la literatura, se investigaron los conceptos de Enseñanza Remota, Enseñanza de Emergencia Remota, además de obstáculos y formación docente en relación al uso de tecnologías. En total, se realizaron cuatro entrevistas a profesionales de la educación activa. Finalmente, realizamos reflexiones en torno a las entrevistas.

Palabras clave: Historia oral; Enseñanza remota; Aprendizaje remoto de emergencia; Formación de profesores.

\section{Introdução}

O desenvolvimento da História Cultural no decorrer do século XX traz consigo a ampliação e diversificação do rol de fontes historiográficas e as suas históricas condições de compreensão e de produção, assim sendo, este novo modo de fazer história abre um leque maior de possibilidades para a pesquisa com a renovação do corpo documental do historiador e, por consequência, estas novas fontes requerem tratamentos metodológicos específicos.

É exigida, deste modo, uma nova postura do historiador onde este deve dispor de um esforço ao questionar a ideia de fonte enquanto o testemunho de uma realidade, passando está a ser concebida como um instrumento de mediação apenas. Assim, a realidade seria analisada através das suas representações, sendo as mesmas consideradas como realidades de múltiplos sentidos. E é neste contexto que passamos a observar o surgimento do esboço do método que ficaria conhecido como História Oral.

A popularização da História Oral como método de investigação teve início na década de 1970, nos Estados Unidos e Europa. A história oral foi validada como potencial para o estudo de acontecimentos e conjunturas a partir da insatisfação dos pesquisadores em relação 
aos métodos quantitativos que eram insuficientes para o estudo da subjetividade e complexidade dos acontecimentos pós-guerra. Assim, os métodos qualitativos, como a História Oral, ganharam visibilidade (ALBERTI, 2013).

No Brasil, o método de pesquisa de História Oral foi apropriado por diversas instituições, que baseadas neste método ampliaram seus programas de estudo e linhas de acervo, estendendo a vários temas de pesquisa. A partir da década de 1990 o declarado "movimento da História Oral” ganhou forças e em 1994 a Associação Brasileira de História Oral (ABHO) foi criada (ALBERTI, 2013).

Internacionalmente, a International Oral History Association (IOHA) foi fundada em 1996 em Gotemburgo, na Suécia, com ampla participação de pesquisadores brasileiros. Desde então, acontecem encontros bienais em congressos internacionais com expressiva participação de estudiosos do Brasil (ALBERTI, 2013).

A História Oral é constituída por "um conjunto sistemático, diversificado e articulado de depoimentos gravados em torno de um tema" (ALBERTI, 2013, p. 18). Dessa forma, o tema escolhido para a pesquisa deve ser recente, pois a memória dos entrevistados deve alcançá-lo sem dificuldades.

Desta forma, no que se refere à História Oral como método, entendemos que ela não documenta nada além de uma versão do passado, ou seja, tomamos a entrevista produzida como documento, no entanto, o objeto documentado não é "o passado como efetivamente ocorreu", mas sim a versão do entrevistado. Entendemos, também, que a participação do pesquisador na produção do documento de História Oral permite uma constante avaliação deste documento ainda durante a sua construção e, segundo Alberti (2013), esta particularidade do documento oral permite recuperar informações que não são possíveis de encontrar em documentos de outra natureza como, por exemplo, experiências pessoais, acontecimentos pouco esclarecidos e impressões particulares.

Assim, os documentos produzidos a partir das entrevistas poderão funcionar como fontes de consulta para temas mais "antigos", porém com uma perspectiva recente. Alberti (2013) recomenda que o estudo de acontecimentos e conjunturas por meio da História Oral deve acontecer no espaço de aproximadamente 50 anos dos eventos.

Revista Devir Educação, Lavras, vol.5, n2., p.249-266 jul./dez., 2021. 
Sendo assim, o tema escolhido para a presente pesquisa é o ensino remoto e suas consequências para a atuação dos professores, visto que este acontecimento, a utilização de ferramentas do ensino remoto em decorrência da pandemia da COVID-19, é recente e ainda está ocorrendo em diversos municípios e escolas brasileiras.

Para Alberti (2013), é impossível realizar entrevistas sem um projeto de pesquisa bem estruturado, com objetivos e orientação teórica clara. Dessa forma, para a presente pesquisa, definimos o seguinte objetivo geral: Compreender, a partir do método da História Oral, como o ensino remoto emergencial impactou a vida docente nos anos de 2020 e 2021 em Guaraí TO. Como objetivos específicos, definimos: a) Apresentar as discussões acerca do método da História Oral; b) Discutir sobre os principais conceitos referentes ao ensino remoto; c) Conhecer as perspectivas docentes sobre essa forma de ensino e; d) Analisar a formação e experiência docente no ensino remoto.

Este breve trabalho se justifica pela necessidade de se entender melhor essa modalidade de ensino sob a perspectiva subjetiva dos próprios docentes, quais as potencialidades e obstáculos do ponto de vista dos entrevistados. "A entrevista da história oral permite também recuperar aquilo que não encontramos em documentos de outra natureza: acontecimentos pouco esclarecidos ou nunca evocados, experiências pessoais, impressões particulares, etc.” (ALBERTI, 2013, p. 32). Portanto, devido ao caráter repentino e pouco planejado do estabelecimento do ensino remoto, a História Oral é adequada para estudo desse acontecimento.

\section{Metodologia}

A História Oral, como método, não é um fim em si mesma, mas um meio de conhecimento. Ela só se justifica na utilização como investigação científica quando articulada com um projeto de pesquisa preliminar.

$\mathrm{Na}$ história oral, a pesquisa e a documentação estão integradas de maneira especial, uma vez que é realizando uma pesquisa, em arquivos, bibliotecas etc., e com base em um projeto que se produzem entrevistas, as quais se transformarão em documentos, que, por sua vez, serão incorporados ao conjunto de fontes para novas pesquisas (ALBERTI, 2013, p. 183).

Portanto, o conhecimento prévio sobre o tema é requisito para a realização de entrevistas.

Revista Devir Educação, Lavras, vol.5, n2., p.249-266 jul./dez., 2021. 
Assim, antes mesmo de se pensar em história oral, é preciso haver questões, perguntas, que justifiquem o desenvolvimento de uma investigação. A história oral só começa a participar dessa formulação no momento em que é preciso determinar a abordagem do objeto em questão: como será trabalhado (ALBERTI, 2013, p. 40-41).

O emprego da História Oral deve prescindir de consultas às fontes disponíveis sobre o tema escolhido já existentes. Dessa forma, esta pesquisa está estruturada em duas etapas: a primeira, de revisão bibliográfica, versará sobre os temas relevantes ao ensino remoto, ensino remoto emergencial e formação de professores.

Uma revisão bibliográfica bem feita não é necessariamente exaustiva, isto é, não se faz necessário ir a todos e a cada um dos textos que tratam do problema. índices e bibliografias comentadas e confiáveis e as próprias revisões bibliográficas feitas, com isenção, por terceiros, são um sucedâneo parcial do trabalho de revisão (RICHARDSON et al., 1999, p. 301).

$\mathrm{Na}$ segunda etapa serão conduzidas as entrevistas temáticas "que versam prioritariamente sobre a participação do entrevistado no tema escolhido" (ALBERTI, 2013, p. 53) com quatro entrevistados a partir de questões semiestruturadas. Buscando-se em sua operacionalização o que se entende pelo conceito de saturação de Daniel Bertaux (1980), conforme recomendado por Alberti (2013). A escolha dos entrevistados

[...] não deve ser predominantemente orientada por critérios quantitativos, por uma preocupação com amostragens, e sim a partir da posição do entrevistado no grupo, do significado de sua experiência. Assim, em primeiro lugar, convém selecionar os entrevistados entre aqueles que participaram, viveram, presenciaram ou se inteiraram de ocorrências ou situações ligadas ao tema e que possam fornecer depoimentos significativos (ALBERTI, 2013, p. 44).

Por último, será feita a sistematização e a análise das entrevistas e a redação da segunda parte da presente pesquisa. Desta forma, como é característico da História Cultural é imprescindível ao historiador possuir em seu 'arsenal' de pesquisa um conjunto de métodos compartilhados de outros saberes para que possa aprofundar e orientar seu olhar e, especificamente para a fonte oral, é imprescindível que o pesquisador possua a atenção voltada à Análise de Discurso pois, ao entender que a principal característica do documento de história oral está na postura do pesquisador em relação a história "que privilegia a recuperação do vivido conforme concebido por quem viveu" (ALBERTI, 1990, p. 5), é necessário compreender, como nos alerta Foucault (1996), que existem componentes materiais e econômicos da opinião, o que se reafirma nas palavras de Pêucheux (1997), ao 
reconhecer que há a necessidade de perceber o ideológico como elemento constituinte do discurso.

\section{Definição de perguntas}

As perguntas semi-estruturadas para as entrevistas foram elaboradas pensando em incentivar a fala e a subjetividade, bem como servindo como um guia para o desenvolvimento e condução das entrevistas.

Dessa forma, as perguntas finais foram essas: 1) Qual a sua idade, nome completo e gênero autodeclarado? 2) Conte-nos um pouco sobre sua trajetória de docente. Formação, quanto tempo trabalha como professor e quais séries/anos trabalha e trabalhou; 3) Como a pandemia afetou a sua vida pessoal? 4) Como a pandemia afetou sua vida profissional? 5) Durante a sua formação profissional, você teve contato com o ensino remoto, seja teórico ou na prática? 6) Como a sua instituição promoveu formação ou aconselhamento sobre a utilização do ensino remoto? 7) O que você pensa sobre o ensino remoto? 8) Quais as principais potencialidades do ensino remoto para você? Por que? 9) Quais os desafios e obstáculos do ensino remoto para você? Por que? 10) Quais as lições que o uso do ensino remoto deixará para o ensino pós-pandemia? Por que? 11) Qual prática do ensino remoto atual deveria ser deixada de ser utilizada no ensino pós-pandemia? Por que?

\section{Revisão bibliográfica}

Nesta seção estudaremos os conceitos de Ensino Remoto, Ensino Remoto Emergencial, além dos obstáculos e a formação de professores em relação ao uso de tecnologias.

\section{Ensino remoto}

“O ensino remoto prioriza a mediação pedagógica por meio de tecnologias e plataformas digitais para apoiar processos de ensino e aprendizagem [...]” (OLIVEIRA et al., 2020, p. 11). O ensino remoto, enquanto elemento estratégico de ensino, é marcado pela característica de não necessitar a presencialidade física das relações educacionais onde, de acordo com Todorov et al. (2009) - enquanto discute a Educação a Distância -, as Tecnologias Digitais de Informação e Comunicação (TDIC) são o aporte que sustentam a lógica e constituem a organização do processo de ensino-aprendizagem no ensino remoto. 
Assim, as práticas institucionais se atentam cada vez mais para a utilização do ensino remoto no escopo educacional, pois permite utilizar plataformas e tecnologias digitais para, segundo Oliveira et al. (2020), mediar pedagogicamente processos educativos de forma dinâmica, flexível e ampla.

O ensino remoto, portanto, exige ir além do simples transporte do fazer pedagógico presencial de sala de aula para espaços digitais, isto é, para garantir a efetividade do processo educacional que utiliza o ensino remoto como estratégia é fundamental a atenção sobre planejamentos, adaptações, recursos e metodologias particulares para o desenvolvimento do processo de ensino-aprendizagem sustentado na interação com as TDIC (OLIVEIRA et al, 2020).

Desse modo, pode-se apontar que existem diferenças bastante relevantes entre o ensino praticado em sala de aula presencialmente e o ensino pautado na mediação tecnológica desenvolvida remotamente e, para Horn et. al. (2015), estas diferenças emergem à evidência especialmente em dois momentos, na abordagem pedagógica do docente e no processo de aprendizagem do estudante.

Ainda, é importante definir que o ensino remoto é comumente confundido e tratado por outras expressões que não condizem como sinônimos para esta estratégia de ensino. Dentre estes, vale destacar a necessidade de pontuar a diferença entre ensino remoto e Educação a Distância (TODOROV, 2009).

De acordo com o parágrafo $1^{\circ}$ do decreto $n^{\circ} 9057 / 2017$, a educação a distância é a modalidade educacional cuja mediação pedagógica se dá por meio de tecnologias de informação e comunicação, as TICs, e permite que as atividades educativas sejam desenvolvidas por estudantes e profissionais de educação presentes em diversos lugares e tempos diversos (BRASIL, 2017).

Dessa forma, a Educação a Distância $(\mathrm{EaD})$ pressupõe distanciamento geográfico e caráter definitivo. $\mathrm{Na} \mathrm{EaD,} \mathrm{um} \mathrm{modelo} \mathrm{pedagógico} \mathrm{específico} \mathrm{é} \mathrm{construído} \mathrm{por} \mathrm{meio} \mathrm{de} \mathrm{uma}$

[...] arquitetura pedagógica composta pelos aspectos organizacionais, de conteúdo, metodológicos, tecnológicos e as estratégias pedagógicas a serem empregadas. Esse modelo é voltado para alunos, professores, tutores e, também, gestores compreendidos como os sujeitos da EaD (BEHAR, 2020, s.n.p.)

Revista Devir Educação, Lavras, vol.5, n2., p.249-266 jul./dez., 2021. 


\section{OO DEVIR EDUCAÇÃO}

ISSN: 2526-849X

A centralidade do processo é no aluno, que está diretamente ligado ao seu curso, que é fundado num currículo, que é orientado por um tutor e o seu pilar é o uso de tecnologias (BARROS E GUERREIRO, 2019). Alves et al. (2003) listam as características do EaD: separação professor-aluno; utilização de meios tecnológicos; organização de apoio (tutoria); aprendizagem independente e flexível; comunicação multidirecional e; educação massiva.

\section{Ensino remoto emergencial (ERE)}

Em 2020 uma nova necessidade educacional foi criada devido à pandemia do vírus SARS-CoV-2 que causa a COVID-19: o caráter de transmissão da doença tornou recomendável o distanciamento social, tornando a escola um espaço de risco de contaminação. Pode-se afirmar que professores e alunos se tornam vetores de transmissão da doença para seus familiares e demais contatos (ARRUDA, 2020). O efeito da COVID-19 no sistema educacional levou à suspensão das aulas ou a mudança para o ensino remoto (ALVES, 2020).

No Brasil, o Ministério da Educação decretou em 17 de Março (BRASIL, 2020), por meio da portaria $\mathrm{n}^{\circ} 343$ a suspensão das aulas presenciais e substituição por atividades nãopresenciais enquanto durasse a pandemia de COVID-19 (VIEIRA E SECO, 2020).

Nesse contexto, a reconfiguração do processo de ensino-aprendizagem adaptado às mudanças decorridas da pandemia, isto é, a utilização de ferramentas como o Microsoft Teams, Google Classroom, Google Meet e Zoom para entrega do conteúdo no lugar das aulas presenciais, foi adotada (ALVES, 2020).

A Organização para Cooperação e Desenvolvimento Econômico (OECD, 2020) produziu uma série de recomendações para o ERE: a) redefinição de objetivos curriculares, rearranjando as prioridades no período de distanciamento social; b) clarificação do papel do professor como suporte à aprendizagem dos alunos, misturando a instrução direta à distância e orientações para uma aprendizagem auto-guiada; 3) a garantia de suporte às famílias mais vulneráveis e o incentivo da participação ativa destas famílias na construção do projeto pedagógico alternativo e; a implementação de um sistema de comunicação adaptado a cada estudante, no sentido de acompanhamento da aprendizagem (VIEIRA E SECO, 2020).

Revista Devir Educação, Lavras, vol.5, n2., p.249-266 jul./dez., 2021. 
Muitas instituições têm implementado respostas rápidas que envolvem tecnologias e apresentando-as erroneamente como Ensino a Distância (EaD). Nesse sentido, as respostas emergenciais de uso tecnológico não podem ser consideradas como $\mathrm{EaD}$, como já falado anteriormente, mas como Ensino Remoto, pois a primeira envolve planejamento prévio, fator que não foi possível estar presente na modalidade de ensino decorrente da pandemia (ARRUDA, 2020).

O Ensino Remoto Emergencial (ERE), de acordo com Hodges et al. (2020) é uma alteração de caráter temporário de entrega de conteúdos como alternativa à situação de crise. Nesse sentido, envolve uma adaptação das aulas previamente pensadas para o modelo presencial para serem disponibilizadas em formato completamente remoto. O ERE pode envolver disciplinas entregues em formato síncrono, de forma que haja maior interação entre docente e alunos ou de forma assíncrona como espaços de discussão e aulas gravadas (ARRUDA, 2020).

\section{Obstáculos do ERE}

Um dos problemas com a adoção repentina ao ensino remoto é o despreparo tecnológico tanto de docentes quanto de alunos no que diz respeito ao acesso a dispositivos adequados e conexão de Internet de qualidade. Portanto, a utilização do ensino remoto em caráter emergencial não oferece superação de desigualdades já existentes na distribuição e qualidade de ensino, que varia de acordo com o perfil econômico do aluno, e ainda revela novos obstáculos (ARRUDA, 2020).

Segundo Arruda (2020), a porcentagem de alunos de escola pública que têm acesso à internet só se mantém alta nas regiões Sul, Sudeste e Centro-Oeste. Os dados apresentados pelo autor demonstram que o celular é o dispositivo mais comum de acesso à internet, sendo o computador um equipamento pouco utilizado cujo uso cai conforme o desenvolvimento econômico da região.

Benedito e Castro Filho (2020) afirmam que a falta de infraestrutura física é um obstáculo para a implementação do ensino remoto. Os autores relatam que já existia um problema de inclusão digital antes da pandemia por falta de laboratórios, insuficiência de equipamentos e limitação do uso aos docentes.

Revista Devir Educação, Lavras, vol.5, n2., p.249-266 jul./dez., 2021. 
Peres (2020) se ocupa dos novos encargos exigidos dos gestores durante a pandemia. Agora, o autor continua, os gestores devem administrar atentos às recomendações de saúde e também, às exigências educacionais em legislação, além das solicitações e necessidades das famílias.

Outras dificuldades presentes no ensino remoto envolvem a diferença geracional entre professor e aluno, tendo em vista a natividade digital, a própria situação de moradia dos alunos que muitas vezes não permite um local de estudos adequado e sobrecarga de trabalho para professores e alunos.

\section{Formação de professores}

Os docentes, de modo geral, não se sentem preparados para assumir as funções da escola mediadas por plataformas digitais pelo nível de letramento digital ou pela questão de limitação tecnológica de acesso aos dispositivos. Desde os anos 1980, o Ministério da Educação e Cultura (MEC) tem incentivado programas de formação continuada digital como o Programa Nacional de Informática na Educação (PROINFO) (BRASIL, 1997). No entanto, a efetividade de tais ações foi baixa por questões políticas, tecnológicas, infra-estruturais e mais (COUTINHO, 2017).

Os docentes, em geral, não foram preparados para as aulas virtuais em seus cursos e só tiveram alguma formação em relação à utilização de tecnologias e recursos educacionais aplicados ao ensino após a pandemia (MELO, 2020).

\section{Análise das entrevistas}

Buscamos profissionais da educação em atividade na cidade de Guaraí - TO antes e durante a pandemia sem recorte de idade, gênero ou graus de docência visando a totalidade do macrocosmo da educação na cidade baseando-se na questão da saturação do método. Ao todo, foram conduzidas quatro entrevistas. Cabe ressaltar que todas as entrevistadas se autodeclararam mulheres.

Geralmente, a educação no nível infantil e fundamental é atribuída às mulheres (COSTA E RIBEIRO, 2011). Os dados coletados nas presentes entrevistas reforçam tal fato. Essa feminização do magistério aconteceu com a associação da escola à maternidade no fim do século XIX e início do século XX (LOURO, 1997). Pela a mulher ser capaz de dar à luz, 
entende-se que também seja a melhor pessoa para lidar com o cuidado de crianças. Ainda, segundo Louro (1997), essa prerrogativa leva ao abandono da docência nestes níveis por homens.

Daquelas que revelaram a própria idade (25\% das entrevistadas), a faixa etária ficou entre 28 e 44 anos, sendo a pessoa com menos tempo de experiência no ensino a mais jovem (6 anos de experiência) e a com mais experiência no ensino (30 anos de experiência) a mais velha. As áreas de formação das entrevistadas variam entre Matemática, Geografia, Biologia, Letras e Pedagogia. Duas das entrevistadas trabalham com os anos finais do ensino médio e as demais, com Ensino Médio e uma delas com Educação de Jovens e Adultos (EJA).

Explorar um fenômeno através da História Oral requer do pesquisador, dentre outras coisas, entender o indivíduo entrevistado enquanto parte de um contexto, ou seja, compreender que este sujeito histórico age no sentido de dialogar com seu entorno para além de ser apenas um personagem que é cooptado e influenciado por sua conjuntura. Com isto em mente iniciamos a entrevista ouvindo como o sujeito entrevistado se percebe no cenário pandêmico.

Duas entrevistadas afirmaram que a pandemia não afetou em nada ou afetou pouco a vida pessoal, uma delas fala que

Pessoalmente não mudou muito a minha rotina, tirando o fato que gosto de viajar e não tenho ido mais [suspiro] [...] Fora isso, ainda continuo indo pra escola atuando na linha de frente para assessorar alunos sem Internet e professores com dificuldades. (Jacqueline)

Dentre as que falaram que a pandemia afetou a vida pessoal, a entrevistada que demonstrou mais tristeza foi a que afirmou um processo de luto:

Perdi pessoas queridas, mas isso ocorre independente de pandemia [hesitação] Procuro não pensar nela, não assisto TV e mantenho o foco no que é possível fazer, não no que deixamos de fazer [pausa] Com a fé em Deus, me fortaleço e vivo um dia de cada vez! (Eliane)

Mesmo as que afirmaram que a pandemia não afetou a vida pessoal sentiram as mudanças na vida profissional. Todas as entrevistadas, Euma, Eliane, Leticia e Jacqueline, demonstram alterações radicais na rotina de trabalho, principalmente no que diz respeito ao aprendizado de novas ferramentas. Uma das entrevistadas comentou sobre a carga de 
trabalho: "Trabalho dobrado, além de todo serviço pedagógico, com a pandemia acabamos tendo que assessorar estudantes que não possuem Internet" (Leticia).

Sobre a opinião das entrevistadas, três afirmam que haviam indícios fortes da adoção do ensino remoto antes da pandemia e que não há dúvidas de que é uma ferramenta do futuro, além de ser uma tendência que poderá se tornar necessária de forma permanente:

[...] atualmente já se fazia o uso, é [rememorando] com plataformas de cursinhos, e até mesmo as universidades, cursos de linguagens [pausa] já era possível fazer on-line. Então o ensino remoto é mais uma ferramenta válida e útil, embora ainda não seja alcançada por todos... [...] (Jacqueline)

Esta é a única resposta que considera a desigualdade de acesso em relação ao ensino remoto. Outros problemas relatados nas reflexões sobre essas questões revelam dificuldade de acompanhar o aprendizado dos alunos e também problemas relacionados à falta de concentração para aprender apenas com recursos tecnológicos. Outro detalhe que vale a pena ressaltar é a adoção do termo "método" por uma das entrevistadas, demonstrando uma falta de conhecimento em relação à estratégia.

As entrevistadas afirmam em sua maioria que não tiveram contato com o ensino remoto, nem mesmo na teoria, nas suas respectivas formações acadêmicas. Jacqueline afirma que na sua graduação ainda não havia acesso à internet, "mal tínhamos acesso a e-mail". Eliane afirma que teve acesso ao ensino remoto apenas nas últimas especializações:

Nas últimas especializações sim, inclusive a atual [reflexão] e para ser sincera, estou amando! Como disse, a pandemia fez a educação avançar anos luz... [...] (Eliane)

Aqui cabe ressaltar a diferença entre as entrevistadas no que se refere a própria experiência em relação à pandemia. Eliane, que se destaca pelo desvio em relação à direção dos demais discursos, é a que revela grande otimismo em todas as respostas em relação à pandemia, que manifesta um discurso permeado por religiosidade e que renuncia ao acesso às informações sobre a pandemia.

Apesar de não ser o objetivo deste estudo, notamos a possibilidade de lançarmos luzes em futuras pesquisas às questões levantadas pela análise do discurso desta entrevistada: a religiosidade e/ou a utilização da informação e suas implicações na percepção do sujeito em relação à sua conjuntura.

Revista Devir Educação, Lavras, vol.5, n2., p.249-266 jul./dez., 2021. 
A maioria das entrevistadas afirmou que obteve formações sobre ensino remoto online a partir das necessidades geradas pela pandemia. Uma delas, Letícia, afirmou que não teve nenhum tipo de formação por parte da instituição que trabalha, nem presencial nem online, o que reforça nossa percepção de que foi um modelo implantado às pressas, talvez um pouco distante ainda das entrevistadas, contradizendo, de certa forma, as respostas anteriores de que era algo iminente.

Sobre as potencialidades do ensino remoto, obtivemos respostas que podem ser agrupadas nas seguintes categorias: a expansão da sala de aula, saída da zona de conforto, estudar na própria casa com apoio e interação com pessoas de outros estados, atendimento às demandas de mercado, comodidade, economicidade, encurtamento de distâncias, complemento de aulas, disponibilização de materiais para aulas, tirar dúvidas, versatilidade e possibilidade de organização da vida acadêmica, novos conhecimentos e novas ferramentas.

Quando perguntadas sobre os obstáculos e desafios do ensino remoto, novamente o assunto da desigualdade de acesso à internet foi citado.

Para mim... o maior desafio é a igualdade de acesso à internet! Ainda existem muitos lugares onde não é possível o acesso do aluno, seja por recursos financeiros ou tecnológicos... Além disso, a maturidade do aluno sobre o aproveitamento das aulas [...] (Jacqueline)

A maior dificuldade é que nem todos têm acesso à internet e pra acontecer o ensino remoto tem que ter uma boa internet.(Euma)

Precisa-se desenvolver melhor as ferramentas que se tem e também suprir as lacunas de acesso a internet (Leticia)

A pandemia fez a desigualdade social ficar ainda mais visível é [pensativa] entre alunos e entre professores. (Eliane)

Entre outros desafios citados, temos a falta de conhecimentos tecnológicos, estrutura, poucos recursos didáticos e não ter contato mais próximo com os alunos. Nesse sentido, percebemos que os docentes estão sobrecarregados pelas novidades do modelo educacional e ainda não se acostumaram às novas técnicas e tecnologias.

As lições que o ensino remoto vão deixar para o ensino pós-pandemia, de acordo com as entrevistas, envolvem a inevitabilidade da tecnologia ser incorporada na prática docente, a necessidade da presença do professor em sala de aula, valorização do profissional de 
educação e necessidade de inovação e reinvenção para que o profissional de educação cumpra seu papel de formador.

Perguntamos também quais práticas do ensino remoto devem deixar de existir póspandemia.

Penso que todas as práticas educativas são bem vindas... a utilização de cada uma delas vai depender exclusivamente do professor, esse ser incrível que tem autonomia para escolher o que é melhor para seus alunos. (Eliane)

Penso que dá pra conciliar as práticas atuais com as antigas, uma não tem que excluir a outra, não! (Jacqueline)

Nenhuma. [pausa] Tudo é uma questão de ser aprimorado. (Letícia)

Desconheço. [...] (Euma)

Neste ponto é importante evocarmos o caráter determinante da Análise de Discurso apontadas por Foucault (1996) e Pêucheux (1997), a investigação pelo pesquisador dos componentes materiais e econômicos do discurso, buscando identificar o ideológico como elemento constituinte do discurso.

Portanto, percebemos, através das respostas à entrevista, que existe uma concepção de que a utilização de meios remotos para o ensino é iminente, inevitável, que "é o futuro", que já vinha sendo utilizada e que traz consigo um conjunto de potencialidades positivas para docência nos próximos anos, porém, as respostas dadas aos questionamentos para o póspandemia centram-se, quase sempre, no alto grau de relevância que estes profissionais atribuem à sua própria prática na docência, ressaltando a necessidade da presença do professor em sala, sua valorização e autonomia. Fica inteligível que o discurso destes sujeitos destaca, sobretudo, que, apesar das tecnologias empregadas, há aquele que é insubstituível apesar das dificuldades, o professor.

\section{Considerações finais}

A escolha do método adequado para conduzir uma pesquisa é essencial para o sucesso da mesma. Dessa forma, acreditamos que quando se trata da subjetividade e necessidade de analisar o entrecruzamento entre a trajetória do indivíduo e sua relação com o tema escolhido, o método da História Oral é o ideal. 


\section{ODEVIR EDUCAÇÃO}

ISSN: 2526-849X

Percebemos nas perguntas cujas respostas necessitavam de mais objetividade - como as perguntas sobre formação das entrevistadas - apresentaram similaridade com o conteúdo obtido por meio da revisão bibliográfica.

Por outro lado, identificamos uma aproximação com o senso comum das respostas às questões mais subjetivas, o que demonstra que as entrevistadas podem não ter refletido anteriormente sobre a questão e não aprofundaram o diálogo. Algo necessário de se analisar em um discurso é que a incerteza em relação à função da própria resposta tende a levar os entrevistados ao senso comum, demonstrando uma tentativa de falar o que o interlocutor deseja ouvir. Da forma que a resposta se caracteriza pela falta de reflexão prévia ou pela tentativa de autoproteção em relação aos próprios discursos. Percebemos tais comportamentos em algumas das entrevistadas.

Nos chamou a atenção, igualmente, as respostas que indicavam o ensino remoto como tendência do futuro visto que, nas perguntas seguintes e anteriores, as respostas em relação à formação dos indivíduos referente a estas ferramentas foram próximas da nulidade.

Admitimos aqui que a condução da entrevista foi marcada pela inexperiência com o método e incapacidade de extrair mais subjetividade, levando à insuficiência das respostas das entrevistadas. Dessa forma, a análise das entrevistas tornou-se igualmente insuficiente. É evidente que o método funciona, mas o pesquisador deve estar preparado para ele, além de desenvolver domínio sobre o processo e apoiar-se de forma segura na condução das entrevistas através do treino.

Os objetivos específicos foram cumpridos a partir dos diferentes métodos de estudo utilizados. O primeiro deles, “apresentar as discussões acerca do método da História Oral” foi realizado por meio de revisão bibliográfica sobre o próprio método tendo como norte os escritos de Verena Alberti (1990; 2013).

O segundo objetivo, "discutir os principais conceitos sobre Ensino Remoto" foi também executado por meio de revisão bibliográfica dialogando com diversos autores, como Arruda (2020), Alves (2020), Hodges et al. (2020), e Oliveira et al. (2020).

Os terceiro e quarto objetivos, "conhecer as perspectivas docentes sobre essa forma de ensino" e "analisar a formação e experiência docente no ensino remoto" foram parcialmente 
alcançados através do método de História Oral, ou seja, gravação, transcrição e análise das entrevistas. No entanto, foram alcançados parcialmente devido à inexperiência do pesquisador em conduzir as entrevistas.

\section{Referências}

ALBERTI, V. História Oral: a experiência do Cpdoc. Rio de Janeiro: Editora FGV, 1990.

ALBERTI, V. Manual de história oral. 3. Ed. Rio de Janeiro: Editora FGV, 2013.

ALVES, L. Educação Remota: entre a ilusão e a realidade. IN: Interfaces Científicas, 8:3, 2020. p. 348-365.

ALVES, D. G.; CABRAL, T. D.; COSTA, R. M. E. M. Ambientes virtuais para educação a distância: uma estrutura de classificação e análise de casos. IN: Cadernos do IME - Skie Informática, Rio de Janeiro, 14:2, 2003.

ARRUDA, E.P. Educação Remota Emergencial: elementos para políticas públicas na educação brasileira em tempos de Covid-19. IN: EmRede: Revista de Educação a Distância, 7:1, 2020. p. 257-275.

BARROS, D.M.V.; GUERREIRO, A.M. Novos desafios da educação à distância: programação e uso de Chatbots. IN: Revista Espaço Pedagógico, 26:2, 2019. p. 410-431.

BEHAR, P.A. O Ensino Remoto Emergencial e a Educação a Distância. IN: Jornal da UFRGS. Julho de 2020.

BENEDITO, S. V. C.; DE CASTRO FILHO, P. J. A educação básica cearense em época de pandemia de Coronavírus (COVID -19): perspectivas e desafios no cenário educacional brasileiro. IN: Revista Nova Paideia: Revista Interdisciplinar em Educação e Pesquisa, 2:3, 2020. p. 58-71.

BERTAUX, Daniel. L'approche biographique. Sa validité méthodologique, ses potentialités. IN: Cahiers Internationaux de Sociologie, Paris, PUF, v. 69, p. 197- 225, juil./déc. 1980.

BRASIL. Ministério da Educação. Programa Nacional de Informática na Educação (PROINFO). Diretrizes. Brasília, junho de 1997.

BRASIL. Presidência da República. Secretaria Geral. Subchefia para Assuntos Jurídicos. Decreto no. 9057, de 25 de maio de 2017. Regulamenta o artigo 80 da Lei no. 9.394 de 20 de dezembro de 1996, que estabelece as diretrizes e bases da educação nacional. Disponível em: $<$ http://www.planalto.gov.br/ccivil_03/_Ato2015 -2018/2017/Decreto/D9057.htm>. Acesso em: 26/06/2021.

BRASIL. Ministério da Educação. Gabinete do Ministro. Portaria no 343 de 17 de março de 2020. Dispõe sobre a substituição das aulas presenciais por aulas em meios digitais enquanto durar a situação de pandemia do Novo Coronavírus - COVID-19.

COSTA, A.P.; RIBEIRO, P.R.M. Ser Professora, Ser Mulher: Um estudo sobre concepções de Gênero e Sexualidade para um grupo de alunas de Pedagogia. IN: Estudos Feministas, 19:2: 336, 2011. p. 474-489. 
COUTINHO, M.S. Contextualizações e recontextualizações nas políticas de TIC e Educação: um estudo sobre o Proinfo Integrado nos NTM da Bahia. Tese de Doutorado em Educação. Bahia: Universidade Federal da Bahia, 2017.

FOUCAULT, M. A ordem do discurso. 3 ed. São Paulo: Loyola, 1996.

HODGES, C.; MOORE, S.; LOCKEE, B.; TRUST, T.; BOND, A. The difference between emergency remote teaching and online learning. IN: EDUCAUSE Review, 17 de março de 2020. Disponível em: <https://er.educause.edu/articles/2020/3/

the-difference-between-emergency-remote-teaching-and-online-learning > Acesso em: 26/06/2021.

HORN, M. B.; STAKER, H.; CHRISTENSEN, C. Blended: Usando a inovação disruptiva para aprimorar a educação. Porto Alegre: Penso, 2015.

LOURO, G.L. Gênero, sexualidade e educação: uma perspectiva pós-estruturalista. Petrópolis: Vozes, 1997.

MELO, I.V. As consequências da pandemia (COVID-19) na rede municipal de ensino: impactos e desafios. Trabalho de Conclusão de Curso de Especialista em Docência no Ensino Superior - Câmpus Ipameri, Instituto Federal Goiano, Ipameri, 2020. 24 p.

OECD. A framework to guide education response to the COVID - 19 Pandemic. Paris: OECD Publishing, 2020.

OLIVEIRA, M.S. de L.; DANTAS, D.M. de M.; LEMOS, A.C.M. de.; ALMEIDA, A.C.S.; BEZERRA, E.L. de S.; SILVA, F.B.M. da.; ALVES, M. do S.V.; ALBUQUERQUE JUNIOR, G.A. de.; REGINO, F.A.; SILVA, I.M.M.; FERREIRA JUNIOR, J.T.; AMORIM, M. da C. de M.; CHAGAS, M. das G.S. das.; CAVALCANTI, M.P.; LINDOSO, R.C.B. Diálogos com docentes sobre Ensino Remoto e planejamento didático. Recife: UFRPE, 2020.

PÊUCHEUX, M. O Discurso: estrutura ou acontecimento. Campinas: Pontes, 1997.

PERES, M. R. Novos desafios da gestão escolar e de sala de aula em tempos de pandemia. IN: Revista Administração Educacional, 11:1, 2020. p. 20-31.

RICHARDSON, R.J.; PERES, J.A.S.; WANDERLEY, J.C.V.; CORREIA, L.M.; PERES, M.H.M. Pesquisa social: métodos e técnicas. São Paulo: Atlas, 1999.

TODOROV, J.C.; MOREIRA, M.B.; MARTONE, R.C.. Sistema personalizado de ensino, educação a distância e aprendizagem centrada no aluno. IN: Psicologia: teoria e pesquisa, 25:3, 2009. p. 289-296.

VIEIRA, M.F.; SECO, C. A Educação no contexto da pandemia de COVID-19: uma revisão sistemática de literatura. IN: Revista Brasileira de Informática na Educação, 28, 2020. p. 1013-1031.

\section{Fontes Orais}

MARINHO, Eliane dos Reis [idade não informada]. Entrevista concedida a Gleyton de Moura Ferreira Silva. Guaraí, TO, 08 março. 2021.

CARDOSO, Letícia Silva [28 anos]. Entrevista concedida a Gleyton de Moura Ferreira Silva. Guaraí, TO, 08 março. 2021. 
ALVES, Jacqueline [33 anos]. Entrevista concedida a Gleyton de Moura Ferreira Silva. Guaraí, TO, 02 abril. 2021.

MOTTA, Euma Sobreira [41 anos]. Entrevista concedida a Gleyton de Moura Ferreira Silva. Guaraí, TO, 02 abril. 2021.

Recebido em: outubro/2021.

Aprovado em: novembro/2021.

Revista Devir Educação, Lavras, vol.5, n2., p.249-266 jul./dez., 2021. 